\title{
Income, Migration and Social Adjustment of the Tribal People in Tripura: A Case Study of the 'Tripuri' Tribe
}

Suman Das ${ }^{\dagger *}$ and Dr Madhushree Das ${ }^{{ }^{*}}$

\section{Abstract}

The purpose of this paper is to explore the relationship between income, migration and social adjustment of the migrated tribal people with special reference to the 'Tripuri' tribe of Tripura, India, with the help of primary data collected from structured interviews using purposive sampling technique. The study reveals that the tribal people who migrated from their native places (rural areas) to urban areas, usually suburbs, have a better economic condition and a decent standard of living. Their livelihood patterns have changed after they have migrated to the urban areas. Here, their income levels have also increased along with expenditure. They live in small houses consuming less land, than they did in their native lands. Their standard of living is much below what they have expected before their decision to migrate. They find it difficult to adjust with the local people and the surroundings. The nature of the employment in urban areas is such that the doors of the organised sector do not open to them easily. They are always last to be hired and first to be fired, and they usually get ill-paid jobs and do not have opportunities for education and training. Their children do not get adequate facilities to enrol in the good schools as the cost of living in the urban areas are very high. They are struggling hard socially and culturally to adapt and adjust in the new milieu far from their lush green land.

Key words: Income, Migration, Tripuri, Tribe, Livelihood, Expenditure, Adjustment, Society, Tripura

\footnotetext{
* Corresponding Authors

+ Suman Das, M.Phil. Student, Department of Geography, Gauhati University Guwahati, Email:sumangeo03@gmail.com

`̃ Dr. Madhushree Das, Assistant Professor, Department of Geography, Gauhati University, Email:madhushreedas@yahoo.com

C2014 Das and Das. This is an Open Access article distributed under the terms of the Creative Commons Attribution License (http://creativecommons.org/licenses/by/2.0), which permits unrestricted use, distribution, and reproduction in any medium, provided the original work is properly cited.
} 


\section{Introduction}

One of the most significant demographic phenomena occurring in many developing countries is the rural to urban migration. Urban areas provide various opportunitiesemployment, decent quality and standard of living, good education facilities-as different from the traditional rural life. Migrants tend to be seen as rational economic agents, being able to judge the differences in opportunities and rewards at home and the place of destination. Recent economic theories have emphasised the role of households and migration strategies as elements of collective portfolios of activities and income sources (Haan, 2000, p.8). The World Bank's 2008 World Development Report on agriculture focuses on the importance of livelihoods, characterised by different strategies-based on farming (market-oriented and subsistence), labour, migration and diversification-and three different types of economy: agriculture-based, transforming and urbanised (World Bank 2007, 76, c.f. Scoones, 2009, p.184). Tripura is the only state in India's North East whose population has been transformed from being a predominantly tribal to non-tribal in the post-Independence period (Tripura Human Development Report, 2007). The tribals of Tripura are mostly agriculturists; many of them still depend on Jhum or shifting cultivation. The Jhumias (Jhumias are the tribals engaged in Jhum cultivation) of Tripura were considered to be self-sufficient in food production in the past, but the situation now has changed radically because the Government of Tripura (GOT) has banned Jhum cultivation and, therefore, the Jhumias are forced to migrate elsewhere for their livelihood (Dasgupta, 1986). Adjustment of people in the social sector is attached to the level of employment, income level, participation in social affairs and other related activities. In this research, we discuss about the income level and the social adjustments of the Tripuri tribe, some of whom were once hardcore Jhumias, dwelling in the scattered villages of the hills of Tripura. After the Jhum cultivation was made illegal, the Tripuris migrated to the urban areas located in the plains in search of employment and opportunities for better standards of living. At the same time, they are trying hard to adjust in the newly settled areas. The article begins with the review of literature followed by a description of the location of the study area. Following this, we discuss and analyse our research findings.

\section{Review of Literature}

Migration tends to be seen as problematic, in academic and policy debates, and in the popular press. According to National Geographic, migration can be of different types: internal migration, external migration, emigration, immigration, return migration and seasonal. ${ }^{1}$ However, migration is often seen as the consequence of ruptures, of environmental disaster, economic exploitation, or political or civil tensions and violence (Haan, 2000). Geographer E.G. Ravenstein developed a series of migration laws and the one that fits our research is that 'most migration is [from] rural to urban'. ${ }^{2}$ This type of migration law tends to be particularly relevant to the poorer stratum of the society. Against this backdrop, we discuss the relationship between income, migration and social adjustment of the Tripuri tribe, who involuntarily moved to the urban areas after GOT imposed ban on Jhum cultivation. Scholars argue that the individual income is an important aspect for income mobility (Burgess et al., 1998). It is assumed to be shared with a household. The concept of mobility, however, is quite distinct from that of economic growth and is closely connected to the notions of efficiency, fairness, and political conflict, which follow paths that are largely unconnected to overall growth (Galiani, 2010). The movement of people from rural to urban

\footnotetext{
${ }^{1}$ Human Migration Guide (3-5) (C) 2005 National Geographic Society. Available at: http://www.nationalgeographic.com/xpeditions/lessons/ 09/g68/migrationguidestudent.pdf (accessed 8 May 2014)

${ }^{2}$ For details, please visit the footnote Human Migration Guide (3-5) referred to in Footnote 1.
} 
areas, also popularly known as urbanisation, is a common phenomenon observed all over the world during a country's process of development (Resosudarmo, et al., 2009). We, however, do not engage with the debates of urbanisation here. Mobility also reflects the extent to which individuals move up (or down) the social ladder compared to their parents. Intergenerational mobility is one of the burgeoning discourses that have become difficult to ignore. Researchers often link intergenerational mobility to migration (Dustmann, 2005; 2008). According to one of the publications of the Organisation for Economic Co-operation and Development (OECD), "[i]ntergenerational social mobility refers to the relationship between the socioeconomic status of parents and the status their children will attain as adults" (OECD, 2010). A number of related factors affect intergenerational social mobility-economic success of an individual, inborn talent, the family and the cultural ambiences in which child (ren) are raised (OECD, 2010). Besides, the public policies also loosely affect intergenerational mobility (OECD, 2010). In a relatively immobile society, an individual's wage, education or occupation tends to be strongly related to those of his/her parents. Studies have shown that the families that are most likely to move are the most disadvantaged and may be characterised by dynamics and processes that are conducive to the development of delinquency and problem behaviour in their children (Gasper et al., 2009). In addition, a person's social capital can often influence her/his mobility and migration (Garip 2008; Pieterse, 2003). Social capital can be understood as the accumulation of resources to which one has access through his or her social network (Bhattacharyya and Vauquline, 2013; Garip, 2008; Coleman, 1988). At the same time, mobility may also be driven by variability in incomes that reflect the risk to which individuals are exposed to in the economy (Atkinson, et al., 1992). Separating the effect of income from the impact of other aspects of the family is a difficult identification problem (Blanden, et al., 2004). Changes in the family structure, financial situation and physical needs create a gap between the desired and the current housing consumption (Tatsiramos, 2006). Household moves are not, of course, inherently problematic. The degree of difficulty in adjustment to a move is dependent on the presence or absence of many factors. For example, the desirability of a move, the reasons for relocating, and the cohesion and support among household members are all part of the context which influence the effects of a move (Coleman, 1988). In a similar context, we examine the income disparity and its impact on mobility of the 'Tripuri tribe' and attempt to explore their social adjustment in the new settings. It is to be noted that Tripura was a tribal-majority state before India's independence; today tribal people constitute only 31 per cent of the total population (Economic Review of Tripura, 2010-11). In the next section, we discuss about the area, people and method.

\section{Area, People and Method}

As discussed above, the study has been carried out among the 'Tripuri tribe' who migrated from the hills to settle in the urban areas in and around Agartala, the capital of the state, located at $23^{\circ} 30^{\prime} 0^{\prime \prime} \mathrm{N}$ latitude and $91^{\circ} 30^{\prime} 0^{\prime \prime} \mathrm{E}$ longitude. The total geographical area of Agartala is $58.84 \mathrm{sq} . \mathrm{km}$. Agartala is the most advanced and urbanised area in the state and flourishes along the banks of river Haora. Among the tribes, 'Tripuri' tribe is the largest with a population of 2, 50,382 persons (Human Development Report, Tripura, 2007). Even from the point of view of migration too, 'Tripuri' tribe is the first tribe in Tripura who had migrated from Mongolia (assumed before 65 $A D$, when Buddhism was introduced in China) to settle in the Tripura hills for their existence. In this research, we investigate the household income, expenditure and the various ways in the Tripuris adapt to the new surroundings in their effort to relocate themselves. With this objective in mind, using structured interviews, we interviewed 70 households out of total 310 households (22.58 per cent) in the fringe of Agartala town. We used, 'structured interview 
schedule' because the migrated Tripuris are not well-educated to read, understand and write the answers of all the questions needed for carrying out this study. Care has been taken to include the houses of different economic conditions along with their views and opinions regarding their adaptation processes in their new milieu. The purposive sampling technique has been used to focus on the target group. The data so gathered have been analysed to obtain a clear exposition.

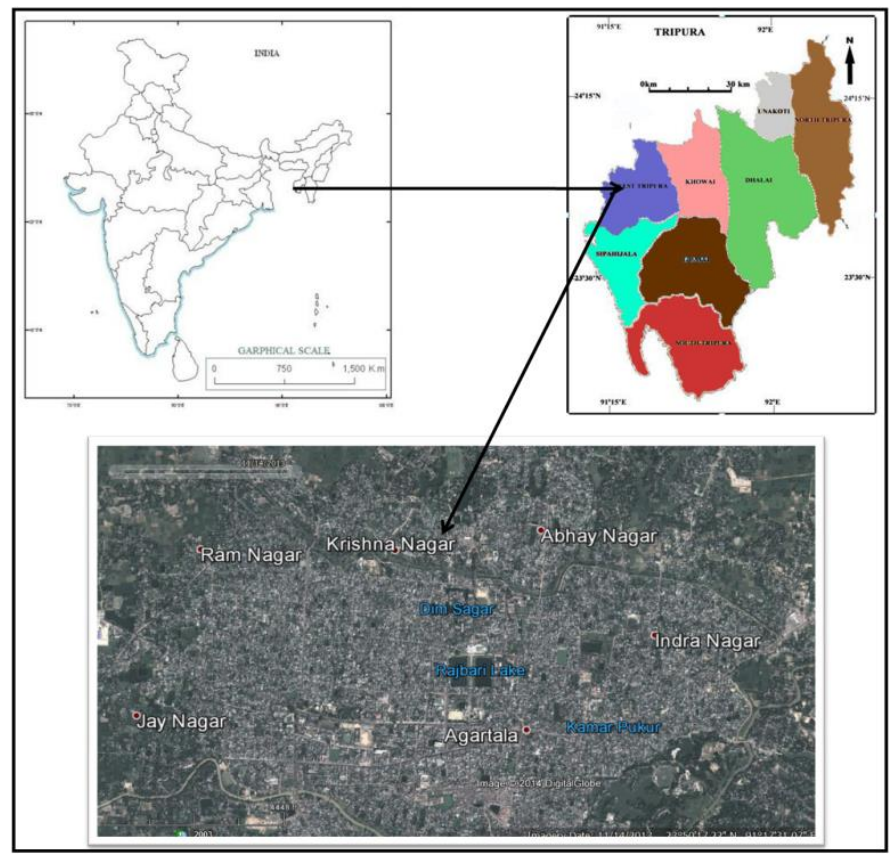

Figure 1: Location Map of the Study Area

\section{Results and Discussion}

\section{Livelihood Pattern of 'Tripuri' Tribe (Before Migration)}

Migrants tend to be seen as rational economic agents. Recent economic theories have emphasized the role of households and migration strategies as elements of collective portfolios of activities and income sources (Haan, 2000). Migration is also viewed as an instrument of social diffusion and cultural integration (Chandna, 2011) From our research, we found that while the Tripuris followed the Ravenstein law of rural to urban migration but we also found evidence of intergenerational mobility (Dustmann, 2005; 2008; OECD, 2010) among many households, while few others used their social capital to migrate to the urban areas (Garip 2008; Pieterse, 2003; Coleman, 1988). The society of the Tripuri tribe is patriarchal. Most of the surveyed households are headed by a male; all the households resettled themselves approximately 10-15 years ago. Our survey also reveals few femaleheaded households. As obvious due to the patriarchal nature of the society, all the maleheaded households are dominated by males, but where males are absent or dead, female take the initiatives to work outside the house to feed their family members. From the survey (Figure 2), it has been observed that before these households migrated to their present location-28.57 per cent were engaged as daily labourers; 21.43 per cent were engaged in jhum cultivation; 25.71 per cent were domestic workers; 15.71 per cent were agricultural labourers and 8.57 per cent were vegetable vendors.

\section{Monthly Household Income of 'Tripuri' Tribe (Before Migration)}

When an individual works hard to earn money in a specific period by using his/her knowledge and skill to fulfil his/her demands and needs 
and feed his/her stomach along with his/her family members is what is termed as income. Here, the household income means total monthly income of the family from all its sources. Among the surveyed households, 18.57 per cent households have an income of ₹ 2000 - 2499; 22.86 per cent of households are earning an income of ₹ 2500 - 2999; 27.14 per cent of households earn in between of ₹3000 3499; 20 per cent within the range of ₹ 3500 3999 and remaining 11.43 per cent of households earn in between ₹ 4000 - 4499.

\section{Monthly Household Expenditure of 'Tripuri' Tribe (Before Migration)}

Expenditure means how much money an individual spends from his/her earned money or income to meet his/her own and family members demands and needs. Here, household expenditure means the monthly expenditure of the family. Among the surveyed households,
17.14 per cent of households spent ₹1500 1999; 24.29 per cent of households spent in between ₹2000-2499; 32.86 per cent of households spent ₹2500 - 2999; 15.71 per cent of households spent ₹3000-3499 and remaining 10 per cent of households spent ₹3500 - 3499.

\section{Tripuri Tribe and Migration}

Migration remains a continuous process. The 'Tripuris' migrated with their family from their native (hilly area) place to the new place (plain areas) due to different reasons: low wages in their native place; non-availability of adequate works; depleting forest-based resources and ban on jhum cultivation; to obtain a decent standard of living; better education for their children; better health care facilities; These factors have pushed them to move from their native place and pulled them to settle in urban areas for opportunity and a modern way of living.

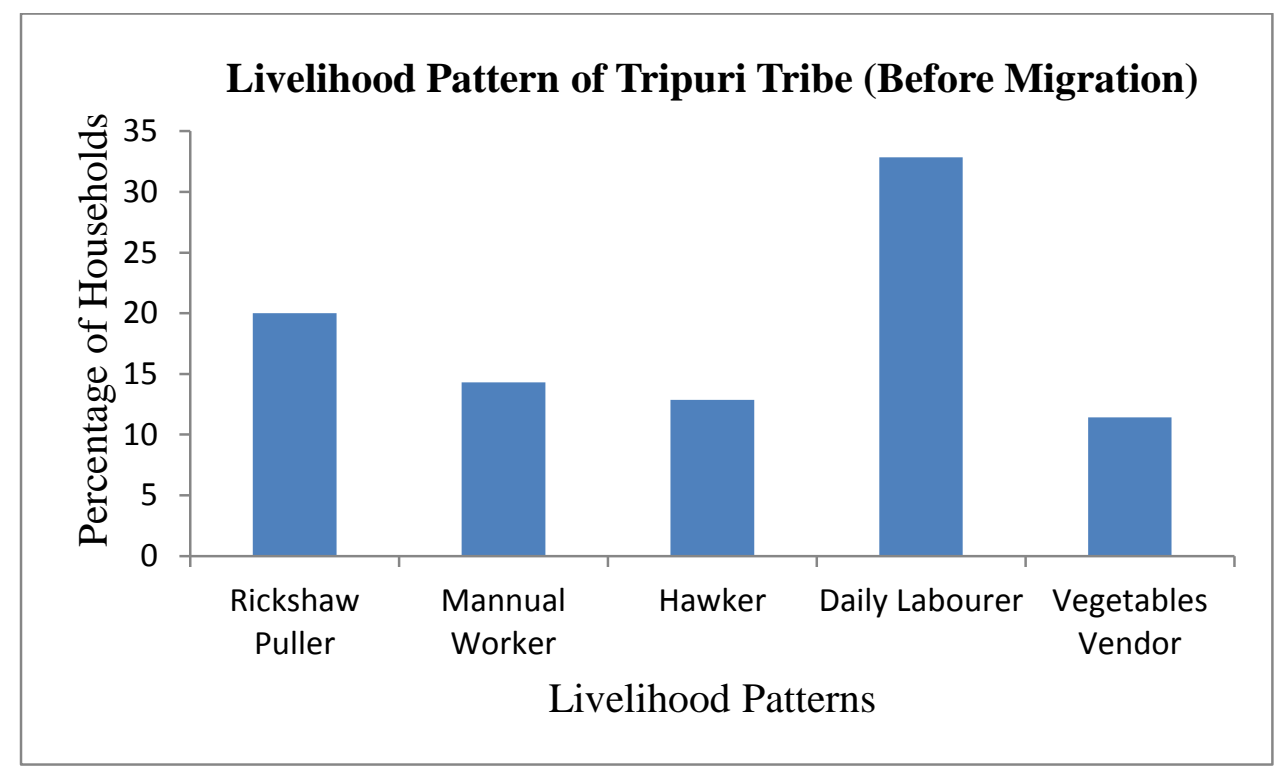

Figure 2: Livelihood Patterns of Tripuri Tribe (Before Migration) Source: Primary Data, 2014

\section{Present Livelihood Pattern of 'Tripuri' Tribe (After Migration)}

Livelihood is a source of income by which we can say how much an individual is earning and what kind of social status he/she is enjoying. Livelihood also denotes the standard of living of an individual. Our research shows that the livelihood patterns of the Tripuris have changed after they migrated to the urban areas. Here, their income levels have increased along with their expenditure. Among the surveyed households, 32.86 per cent are engaged as daily labourers; 20 per cent are rickshaw pullers; 12.86 per cent hawkers; 8.57 per cent are employees in the shops; 11.43 per cent are vegetables vendors; 14.29 per cent are engaged in manual activities like fencing, clearing (meaning, to clear or cut down the unwanted bushes and trees of the houses to keep them clean and tidy), etc. (Figure 3). 
As one of our respondents in reply to our question responded in the following way: "I engage myself in all sorts of unskilled activities be it a daily wage laborer, a rickshaw puller, a hawker or a vegetable vendor to earn bread and butter for my family. Though I have to work hard here and my expenses are higher, I earn more money than what I had been earning in my native village."

Evidently, the nature of the employment in urban areas is such that the doors of the organised sector do not open to them easily. They are always last to be hired and first to be fired, and fail to avail opportunities for education and training.

Present Monthly Household Income of 'Tripuri' Tribe (After Migration)

As stated above, the Tripuris migrated from their native place to the new place for a better living. Among the surveyed households, 14.29 per cent earn in between ₹ 3000 - 3999; 32.86 per cent of households earn ₹ 4000 - 4999; 30 per cent of household's income ranges between ₹5000 - 5999 and 22.86 per cent of households earn ₹6000-6999.

\section{Table 1: Past Monthly Income and Expenditure Pattern of Migrated Tripuris}

\begin{tabular}{cccc}
$\begin{array}{c}\text { Past Monthly Household } \\
\text { Income (in ₹) }\end{array}$ & $\begin{array}{c}\text { Sample } \\
\text { Household } \\
\text { (in percentage) }\end{array}$ & $\begin{array}{c}\text { Past Monthly Household } \\
\text { Expenditure (in ₹) }\end{array}$ & $\begin{array}{c}\text { Sample } \\
\text { Household } \\
\text { (in percentage) }\end{array}$ \\
\hline $2000-2499$ & 18.57 & $1500-1999$ & 17.14 \\
\hline $2500-2999$ & 22.86 & $2000-2499$ & 24.29 \\
\hline $3000-3499$ & 27.14 & $2500-2999$ & 32.86 \\
\hline $3500-3999$ & 20.00 & $3000-3499$ & 15.71 \\
\hline $4000-4499$ & 11.43 & $3500-3999$ & 10.00
\end{tabular}

Source: Primary Survey, 2014

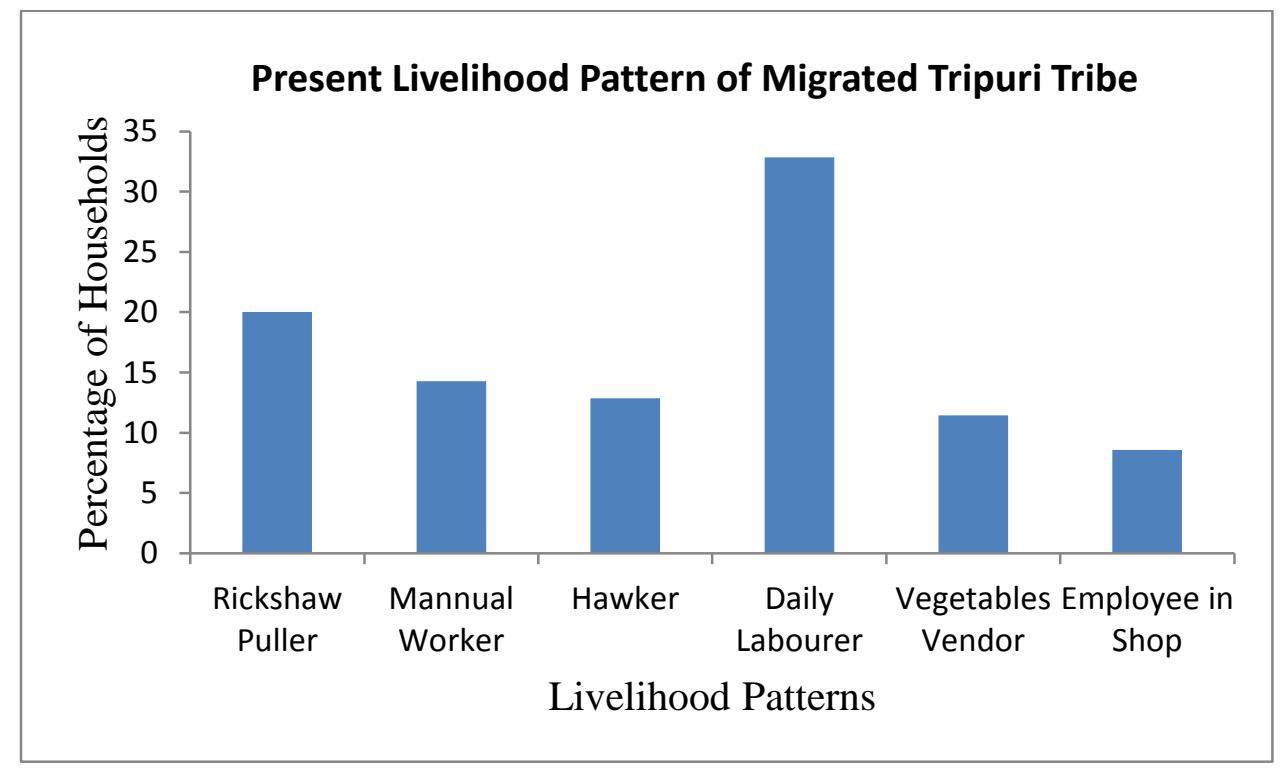

Figure 3: Present Livelihood Pattern of Migrated 'Tripuri' Tribe (After Migration) Source: Primary Data, 2014 
Table 2: Present Monthly Income and Expenditure Pattern of Migrated Tripuris

Present Monthly Household

Income (in ₹)

Sample

Household

(in percentage)
Present Monthly Household

Expenditure (in ₹)
Sample

Household

\begin{tabular}{cccc}
\hline $3000-3999$ & 14.28 & $3000-3499$ & 11.43 \\
\hline $4000-4999$ & 32.86 & $3500-3999$ & 18.57 \\
\hline $5000-5999$ & 30.00 & $4000-4499$ & 37.14 \\
\hline $6000-6999$ & 22.86 & $4500-4999$ & 24.29 \\
\hline & & $5000-5499$ & 8.57
\end{tabular}

Source: Primary Survey, 2014

Present Monthly Household Expenditure of 'Tripuri' Tribe (After Migration)

The migrated Tripuris spend their money according to the needs and demands of his/her family. Among the surveyed households, 11.43 per cent of households spend ₹3000 - 3499; 18.57 per cent of households spend in between ₹3500 - 3999; 37.14 per cent of households spend ₹4000 - 4499; 24.29 per cent of households spend $₹ 4500$ - 4999 and the remaining 8.57 per cent of households spend ₹5000 - 5499. It is interesting to note that while in their native village their monthly expenditure pattern ranged in between $₹ 1500$ - 4000. It hardly exceeded ₹4000 per month, but after shifting, their expenditure pattern increased drastically because in the urban areas these migrated Tripuris earn more than what they earned in their native land.

Social Adjustment of Migrated People of 'Tripuri' Tribe

Social adjustment implies the adjustment of people in the new society from their traditional society and how they are adapting to the new environment along with their associated social activities. Here among the surveyed households, the societal position of the people especially those who were engaged in the livelihood pattern as mentioned above is low, meaning their income is not sufficient to maintain a decent standard of living. They usually settle themselves in the sub-urban areas, where the cost of living is low as their income is not high. The surveyed data illustrates the fact that 100 per cent of them live in rented houses of which 82.86 per cent of families live in kaccha (non-cemented) houses because their income cannot support a better living for them. Their average household's size is 4.3. Their food habits are very simple but have undergone drastic changes due to the changing urban lifestyles. It may be mentioned here that the habit of taking baked bread in breakfast has penetrated among them in place of fried rice flakes (locally called 'Muri'). Their traditional food habits, which used to be wild edible leaves, roots and green vegetables and variety of spices collected locally from the forest, have also changed. Our survey reveals an interesting fact, when questioned about the nature of relationship they possessed with the local people and the pattern of assimilation among them; it has been found that 54.29 per cent of Tripuris were having cordial relation with the locals and are trying to adapt to their culture and customs and the rest 45.71 per cent Tripuris were indifferent and do not have any relationship with the localities. It may be mentioned here that the active participation of migrated Tripuris in the social programmes like the cultural functions, social gatherings, community development programmes, etc. is quite low, only (28.57 per cent) because the migrated Tripuris has their own beliefs and value systems, own rites and rituals which do not match with the ideology of the local people. Moreover, they cannot communicate with the local people because they speak a different language (Kokborok), while the local people speak a mixed Bengali language. It is because of this barrier they avoid the social functions and gatherings. Schooling of children of this migrated tribe is the most significant aspect of social adjustment. Among the surveyed households, 92.86 per cent of children are found to study in the Government 
schools and remaining 7.14 per cent of children were studying in the private schools. The Government schools are not well-equipped and do not have proper teaching-learning aid. Even the teachers are not acquainted with the modern techniques of teaching and hence, the level of education is deteriorating in the Government schools. Many parents prefer to send their wards to the private schools even though their economic conditions do not allow them to do so. In other words, their children do not get adequate facilities to enrol in the good schools as the cost of living in the urban areas is very high. Therefore, in this way, the 'Tripuri' tribe is trying hard to adjust in their new social environment far from their own native land.

\section{Conclusion}

The above analysis reveals that with a population size of 2,50,382, 'Tripuris' is the largest in number among all the tribal groups of Tripura, India. They have migrated from their native place where they were engaged in primary and other economic activities to the urban areas in search of employment and better standard of living. The poor economic condition and lack of Government facilities accelerate the wave of migration. Their source of income in their native place was limited and the wages they earned was very less, ranging between ₹2000 - 5000 per month. After they migrated to the urban areas, their livelihood patterns have changed from their past livelihood patterns. In the urban areas though they started earning more than what they earned in their native place but along with this, their expenditure have also increased. They are mostly engaged as marginal workers and the doors of the organised sectors do not open to them easily. They live in small houses consuming less land, than they did in their native places. Their standard of living is much below what they had expected prior to their decision to migrate. They find difficulty in adjusting with the local people and the surrounding. Their children do not get adequate facilities to enrol in the good schools as the cost of living in the urban areas is very high. They are struggling hard socially and culturally to adapt and adjust in the new milieu far from their lush green land and their struggle continues.

\section{References}

Atkinson, A., B., Bourguignon, F., and Morrisson, C., 1992. Empirical Studies of Earnings Mobility. In Lesourne, J., and Sonnenschein, H. (eds), Fundamentals of Pure and Applied Economics, Volume 52, Harwood Academic Publishers, Philadelphia

Bhattacharya, R. and Vauquline, P., 2013. A Mirage or a Rural Life Line?: Analysing the Impact of Mahatma Gandhi Rural Employment Guarantee Act on Women Beneficiaries of Assam, Space and Culture, India, 1 (1), 83-101

Blanden, J., Goodman, A., Gregg, P., and Machin, S., 2004. Changes in Intergenerational Mobility in Britain. In Corak, M. (ed.) Generational Income Inequality. Cambridge: Cambridge University Press

Burgess, M., Simon and Propper, Carol., 1998. An Economic Model of Household Income Dynamics, with an Application to Poverty Dynamics among American Women, Centre for Analysis of Social Exclusion, London School of Economics, CASE paper- 09

Chandna, R., C., 2011. Geography of Population: Concepts, Determinants and Patterns, Kalyani Publishers (New Delhi), ISBN 978-81-272-66462

Coleman, James S., 1988. Social Capital in the Creation of Human Capital. American Journal of Sociology 94, 95-120

Dasgupta, Malabika, 1986. Jhumias of Tripura, Economic and Political Weekly Vol. XXI, No. 44 and $45,1-8$

Dustmann, Christian, 2005. Intergenerational Mobility and Return Migration: Comparing Sons of Foreign and Native Born Natives, Discussion Paper Series, CDP No 05/05 Centre for Research and Analysis of Migration Department of Economics, University College London

Dustmann, Christian, 2008. Return Migration, Investment in Children and Intergenerational Mobility Comparing Sons of Foreign and Native- 
Born Fathers, The Journal of Human Resources, XLII, 2, 299-323

Economic Review of Tripura., 2010-11. Directorate of Statistics and Economics, Govt. of Tripura, Agartala

Garip, F., 2008. Social Capital and Migration: How do Similar Resources Lead to Divergent Outcomes?, Demography, 45 (3), 591-617

Galiani, Sebastian., 2010. Social Mobility: What Is It and Why Does It Matter?, Documento de Trabajo Nro. 101 Junio, CEDLAS- 2010, ISSN 1853-0168

Gasper, Joseph; DeLuca, Stefanie, and Estacion, Angela 2009. Coming and Going: Explaining the Effects of Residential and School Mobility on Adolescent Delinquency, Social Science Research, XXX Elsevier Publishing House

Gray, et al., 2013. Examining Social Adjustment to College in the Age of Social Media: Factors Influencing Successful Transitions and Persistence, Computers \& Education, 67, 193207

Haan, de, Arjan, 2000. Migrants, Livelihoods, and Rights: The Relevance of Migration in Development Policies, Social Development Working Paper No. 4
OECD, 2010. A Family Affair: Intergenerational Social Mobility across OECD Countries, Economic Policy Reforms Going for Growth, Part-II, Chapter-5

Pieterse, Nederveen, 2003. Social Capital and Migration: Beyond Ethnic Economics, Ethnicities, 3 (1), 5-34

Resosudarmo, et al., 2009. The Socio-economic and Health Status of Rural-Urban Migrants in Indonesia, The SMERU Research Institute Jakarta, Working Paper, ISBN 978-979-3872-711

Scoones, Ian, 2009. Livelihoods Perspectives and Rural Development, Institute of Development Studies, The Journal of Peasant Studies, 36 (1), 171-196

Tatsiramos, Konstantinos, 2006. Residential Mobility and Housing Adjustment of Older Households in Europe, Institute for the Study of Labor, Discussion Paper No. 2435

Tripura Human Development Report, 2007. Directorate of Economics \& Statistics, Planning (Statistics) Department, Government of Tripura, Agartala 